\title{
Association of Intrarenal Resistance Index and Systemic Atherosclerosis After Kidney Transplantation
}

\author{
PHILIPP KÖGER ${ }^{1}$, STEPHAN ENGELBERGER ${ }^{2}$, CHRISTOPH THALHAMMER $^{3}$, \\ RUDOLF WÜTHRICH ${ }^{4}$, MARIE-LUISE VALENTIN ${ }^{5}$, NILS KUCHER ${ }^{5}$ and ROBERT K. CLEMENS ${ }^{2}$ \\ ${ }^{1}$ Vascular Practice Wil and University Zurich, Zurich, Switzerland; \\ ${ }^{2}$ Vascular Center, Cantonal Hospital Baden, Baden, Switzerland; \\ ${ }^{3}$ Clinic for Angiology, Cantonal Hospital Aargau, Aargau, Switzerland; \\ ${ }^{4}$ Clinic for Nephrology, University Hospital and University Zurich, Zurich, Switzerland; \\ ${ }^{5}$ Clinic for Angiology, University Hospital and University Zurich, Zurich, Switzerland
}

\begin{abstract}
Background/Aim: Patients after kidney transplants are at risk of cardiovascular morbidity. An elevated resistance index (RI) is associated with renal graft failure, while a decreased RI can be due to a renal artery stenosis. The RI can also be measured in the carotid artery. Whether a correlation between intrarenal RI after kidney transplant in adult patients and the RI of the internal carotid artery exists is still unclear. Patients and Methods: In this prospective cross-sectional study, RI of kidney transplants and of the internal carotid artery were measured with duplex sonography. Carotid intima-media thickness as well as the Framingham risk score and the Augmentation index, all known markers of atherosclerosis, were assessed. Correlations between the RI in Carotid artery and the RI of the kidney transplant were based on Spearmen test with the level of significance set at $p<0.05$. Results: Ninety-eight consecutive patients [60\% male, mean age of $48.7( \pm 15.6)$ ] were included. The mean interval after transplantation was $27.5( \pm 8.5)$ months and mean serum creatinine was 308 $( \pm 220.3) \mathrm{mmol} / \mathrm{ml}$ The $R I$ of the internal carotid artery and the renal transplant were significantly correlated $(p<0.05)$. A correlation between the RIs and the Augmentation Index was found. Conclusion: The RI of the kidney transplant is correlated with the RI of the carotid artery and to markers of general atherosclerosis. This observation may be helpful to identify patients after kidney transplant with higher risk
\end{abstract}

This article is freely accessible online.

Correspondence to: Robert K. Clemens, Vascular Center Cantonal Hospital Baden, Im Ergel 1, 5404 Baden, Switzerland. Tel: +41 449222308, e-mail: robert.clemens@gmx.net

Key Words: Renal transplant, resistance index, cardiovascular risk factors, renal transplant stenosis. for cardiovascular events and gain indirect information on transplant renal artery stenosis.

Kidney transplant is the most frequently performed organ transplant (1). Computed tomography (CT) and coronary Angio-CT are used for risk stratification in kidney transplant candidates for risk stratification before transplantation (2). It is the treatment of choice in end-stage renal disease (ESRD) and is ideally performed before initiation of hemodialysis (3). It is also more cost-effective than long-term dialysis (4). Color-coded Doppler sonography (CCDS) is part of the postoperative surveillance (5). The surveillance may start as early as during, but should be initiated immediately after transplant (6). Besides the diagnosis of arterial or venous obstruction, the intrarenal vascular resistance, called Resistance Index (RI) is measured (7). While the RI can be difficult to measure in orthotope kidneys it is often easier to assess in the more superficial transplant in the iliac fossa. Nonetheless, accessibility can be limited due to different factors such as pain, obesity, flatulence amongst others. The RI has been a proven to be sensitive marker of graft dysfunction, but is unspecific (8). The RI of the kidney transplant adapts rapidly to the host (9). An elevated RI of 0.80 (normal range=0.6-0.7) or higher indicates an unfavorable prognosis of renal function as well as increased mortality (10). A decreased RI can be a sign for a renal stenosis (11). RI measurement is observer dependent (12). There is a significant association between an increased RI and markers of generalized atherosclerosis such as the Framingham risk score (FRS), the Carotid Intima-MediaThickness (CIMT) and the Ankle-Brachial-Index (ABI) but not for renal function measured with the glomerular-filtrationrate (GFR) (13). Krumme et al. showed that recipient age is associated with the RI (14). The RI of the internal carotid artery is a functional parameter for the generalized atherosclerotic process and is correlating well with wall 
Table I. Possible causes of an elevated resistance index [adapted from (30)].

\begin{tabular}{lc}
\hline Renal & Extrarenal \\
\hline Acute rejection & Bradycardia \\
Chronic rejection & Acute/chronic hydronephrosis \\
Renal vein thrombosis & Cyclosporine toxicity \\
Acute tubular necrosis & Hematoma, lymphocele \\
Pyelonephritis & Compression by transducer \\
Glomerulonephritis & Hypotension \\
\hline
\end{tabular}

hypertrophy measured as CIMT as a morphologic correlation to atherosclerosis (15). Gerhart et al. showed that indices of systemic atherosclerosis such as the Framingham risk score are superior to ultrasound resistance indices for prediction of allograft survival (16). Augmentation index (AIx) is a parameter measured by pulse wave analysis (PWA) used as a surrogate measure of arterial stiffness and is a useful marker of cardiovascular events (17). A correlation between the RI of renal transplants and the carotid artery as well as the RI of the transplant and IMT, AIx and FRS has never been investigated, but could theoretically be used as a tool to identify patients after kidney transplant with higher risk for cardiovascular events. If the renal RI and the carotid RI were associated, this finding could be useful for the observer if the graft artery and/or the IR was difficult to assess, and a renal artery stenosis suspected: a renal artery stenosis would lead to a discrepant renal-carotid RI.

\section{Patients and Methods}

Patients after kidney transplant, that gave their informed consent were consecutively included. All patients that gave informed consent to participate in the study and could withdraw from the study any time. Informed consent was obtained from all subjects. If subjects were under 18 , informed consent was obtained from a parent and/or legal guardian.

Patients were consecutively included in this prospective crosssectional study. They were transferred to our department for CKDS for routine surveillance of grafts or with questions such as renal graft stenosis or AV-fistula after transplantation or decreasing GFR.

Exclusion criterion was the presence of any carotid or renal artery stenosis. Baseline values (including creatinine and creatinine that were used to estimate the GFR using the CKD-EPI Creatinine Equation (2009)) were extracted from the patient chart (18). Patients were included regardless of their GFR to have a broad spectrum of patients as seen in daily practice in a genuine setting. All patients received standard medical treatment for their allograft kidney, including immunosuppressive therapy with steroids and tacrolimus or cyclosporine. Kidneys were transplanted to the iliac fossa with the external artery and vein being the supply vessels.

Colour-coded duplex sonography (CCDS) and spectral analysis. Recognizing pathological findings like stenosis or arterio-venous

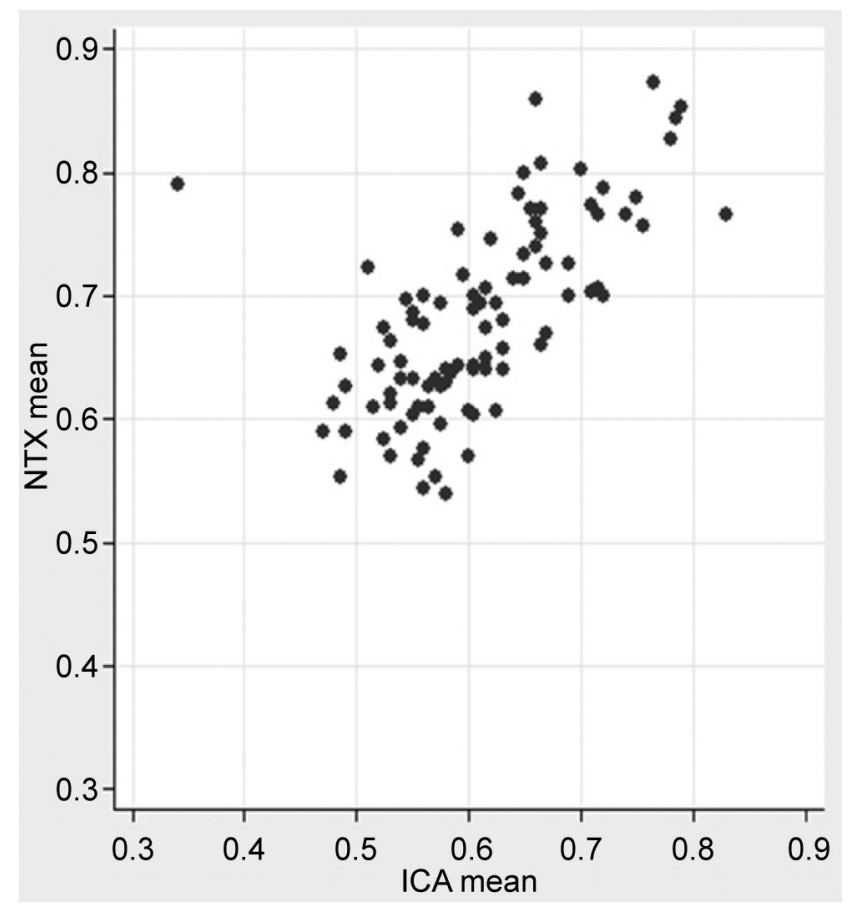

Figure 1. Correlation of kidney transplant-RI and RI of the internal carotid artery. NTX: RI of kidney transplant. ICA: RI of internal carotid artery.

fistulas becomes considerably easier with CCDS. To demonstrate non-perfused areas, application of a signal enhancer (contrast agent) may be particularly useful $(19,20)$. Various causes of an elevated RI value are displayed in Table I.

Ultrasound was performed with the ultrasound system iU22 (Philips, Best, Netherlands), a high-resolution ultrasound with integrated software (QLAB). Board certified investigators according to a standardized protocol performed all CCDS. Three representative IMT measurements (QLAB) were bilaterally performed in the wall of the common carotid arteries at defined sites. These six intimamedia thickness readings were averaged to give the mean common carotid IMT. The intra-renal resistance index and the index of the carotid artery were measured in the same session.

For the assessment of arterial stiffness using the AIx radial artery pulse wave analysis was performed noninvasively with the SphygmoCor system (AtCor Medical; Sydney, Australia) by a single observer with patients in supine position. Augmented pressure was defined as the difference between the second and the first systolic peak, and AIx was expressed as percentage of the pulse pressure (difference between systolic and diastolic pressure).

A standardized questionnaire was used to compute the Framingham Risk score using the following data: smoking status, record a history of smoking, cholesterol levels, blood pressure, medication for arterial hypertension, diabetes, a family history of premature-onset cardiovascular disease (defined as myocardial infarction or stroke before the age of 65 in first-degree relatives), and current drug intake. The Framingham risk score was calculated for all patients at the webpage of the National Heart, Lung and Blood Institute website (http://www.nhlbi.nih.gov/guidelines/cholesterol/). 
Table II. Baseline characteristics of included patients.

\begin{tabular}{lc}
\hline & Mean $(\mathrm{SD})$ \\
\hline Age, years & $48.7( \pm 15.6)$ \\
Female, male \% & 40,60 \\
Months after kidney transplant & $27.5( \pm 8.5)$ \\
GFR $(\mathrm{ml} / \mathrm{min})$ & $29.2( \pm 19.6)$ \\
Creatinine $(\mu \mathrm{mol} / \mathrm{l})$ & $308.0( \pm 220.3)$ \\
Cholesterol $(\mathrm{mmol} / \mathrm{l})$ & $4.8( \pm 0.9)$ \\
High density lipoprotein $(\mathrm{mmol} / \mathrm{l})$ & $1.2( \pm 0.32)$ \\
Systolic blood pressure $(\mathrm{mmHg})$ & $137.4( \pm 18.0)$ \\
Diastolic blood pressure $(\mathrm{mmHg})$ & $78.7( \pm 12.1)$ \\
FRS\%10J & $8.2( \pm 10.5)$ \\
\hline
\end{tabular}

SD: Standard deviation, FRS: Framingham risk score.

Data management and statistical analysis was performed with the STATA software (StataCorp. 2019. Stata Statistical Software: Release 16. College Station, TX: StataCorp LLC). As the data is not normally distributed but monotonically related; we did not use Pearson correlation - Spearman does not carry assumptions about the distribution of the data. Unless indicated otherwise, continuous data are expressed as means \pm standard deviation, and compared by Kruskal-Wallis Test. To analyze the association of renal transplant resistance index with various indicators we categorized data firstly in tertiles where possible. Subsequently we compared mean RI of kidney transplant and the internal carotid RI with the tertiles with Kruskal-Wallis test (Figure 1). Correlations between the RI in carotid artery and the RI of the kidney transplant were based on Spearmen test with the level of significance set at $p<0.05$.

Ethics approval. The Institutional Committee on clinical investigation of the University Hospital Zurich and the cantonal ethic committee Zurich approved this prospective study. All methods were carried out in accordance with relevant guidelines and regulations according to the ethics committee and the Declaration of Helsinki. The study is registered under NCT01001065 at ClinicalTrials.gov.

\section{Results}

Ninety-eight patients (60\% males, $40 \%$ females) were consecutively evaluated between September 2009 and September 2015 and included in this prospective study. The mean interval after transplantation was 27.5 months $( \pm 8.5)$ months and the mean age $(48.7 \pm 15.6)$ years. All patients in this prospective cross-sectional cohort received their renal transplant more than 18 months ago.

Patients were consecutively included regardless of their creatinine levels to give a genuine clinical setting without selection bias. The mean serum creatinine was $308 \mathrm{mmol} / \mathrm{ml}$ $( \pm 220.3)$. Twenty-eight $(28.6 \%)$ patients were active smokers, 72 patients $(73.5 \%)$ were under antihypertensive medication. Baseline characteristics are presented in Table II. A significant correlation of the renal and the carotid RIs
Table III. Spearman's ranked correlation of NTX RI and various indicators.

\begin{tabular}{lccc}
\hline & $\begin{array}{c}\text { Correlation } \\
\text { coefficient }\end{array}$ & $p$-Value & $\begin{array}{c}\text { Number of } \\
\text { observations }\end{array}$ \\
\hline Creatinine & -0.04 & 0.67 & 98 \\
GFR & 0.00 & 0.99 & 98 \\
IMT carotid mean & 0.58 & $<0.05$ & 98 \\
AIx & 0.43 & $<0.05$ & 47 \\
\hline
\end{tabular}

GFR: Glomerular filtration rate. IMT: intima-media thickness. AIx: Augmentation index.

with the augmentation Index (AIX) with a coefficient of 0.43 $(p<0.05)$ and the CIMT with a correlation coefficient of 0.58 $(p<0.05)$ as shown in Table III was found. Calculations based on Spearman Test did not show a correlation with renal function and RI. Only patients with a low FRS had a significant correlation with the transplant RI with a coefficient of $0.38(p<0.05)$ as shown in Table IV.

\section{Discussion}

Patients after kidney transplant have an elevated risk for cardiovascular events (21). Risk stratification, therefore, depends as well on markers of cardiovascular events. Intrarenal RI is a routinely assessed complex parameter that reflects the arterial compliance and pulsatility rather than renal vascular resistance (22). The function of the allograft is as well routinely assessed with CCDS including the RI $(23,24)$. RI can also be reliably measured in renal grafts if accessible (25). Päivärinta et al. assessed the kidney function with PET-CT and RI measurements with CCDS to show that the RI was correlated with perfusion and fibrosis of the transplants (26). Boran et al. found an association between recipients with proteinuria $<1,000 \mathrm{mg} / 24 \mathrm{~h}$, and elevated RIs (27). Radermacher et al. showed that an elevated RI was a strong predictor of allograft loss (10), but there is an ongoing discussion if the RI was sensitive and specific enough to discriminate between the different causes for acute graft failure (28). In our population of 98 adult patients with previous kidney transplants we found a significant correlation between the mean kidney transplant RI and mean internal carotid artery RI with a correlation coefficient of $0.69(p<0.05)$.

Measurement of flow in the graft vessels and of the measurements of the RI help to exclude early thrombotic complications (8). Further, there is evidence that the RI obtained during the first 6 months after transplant failed to predict kidney allograft failure, whereas the RI obtained 1218 months after transplantation appeared to be useful to predict long-term allograft outcomes (29). All patients in this 
Table IV. Association of RI (NTX mean) with various indicators.

\begin{tabular}{|c|c|c|c|c|}
\hline Age* & $15-42$ & $43-57$ & $58-76$ & Kruskal Wallis \\
\hline RI NTX mean & $0.62 \pm 0.06$ & $0.68 \pm 0.06$ & $0.75 \pm 0.06$ & \\
\hline $\begin{array}{l}\text { Correlation } \\
\text { coefficient }\end{array}$ & 0.24 & 0.33 & -0.06 & $\mathrm{Chi}^{2}: 43.00$ \\
\hline$p$-Value & 0.18 & 0.06 & 0.76 & $p$-Value: $<0.05$ \\
\hline GFR* & $5-12$ & $13-40$ & $42-60$ & \\
\hline RI NTX mean & $0.68 \pm 0.07$ & $0.68 \pm 0.08$ & $0.68 \pm 0.08$ & \\
\hline $\begin{array}{l}\text { Correlation } \\
\text { coefficient }\end{array}$ & -0.12 & -0.19 & -0.01 & $\mathrm{Chi}^{2}: 43.00$ \\
\hline$p$-Value & 0.48 & 0.33 & 0.94 & $p$-Value: 0.57 \\
\hline Creatinine* & $56-157$ & $158-390$ & $398-987$ & \\
\hline RI NTX mean & $0.69 \pm 0.08$ & $0.69 \pm 0.08$ & $0.67 \pm 0.07$ & \\
\hline $\begin{array}{l}\text { Correlation } \\
\text { coefficient }\end{array}$ & 0.08 & 0.18 & 0.25 & $\mathrm{Chi}^{2}: 1.08$ \\
\hline$p$-Value & 0.65 & 0.31 & 0.17 & $p$-Value: 0.58 \\
\hline Cholesterin* & $2.7-4.4$ & $4.5-5.2$ & $5.3-7.6$ & \\
\hline RI NTX mean & $0.70 \pm 0.09$ & $0.67 \pm 0.07$ & $0.67 \pm 0.08$ & \\
\hline $\begin{array}{l}\text { Correlation } \\
\text { coefficient }\end{array}$ & -0.18 & -0.11 & 0.26 & Chi $^{2}: 1.71$ \\
\hline$p$-Value & 0.32 & 0.50 & 0.19 & $p$-Value: 0.42 \\
\hline $\begin{array}{l}\text { HDL } \\
\text { Cholesterin* }\end{array}$ & $0.62-1.06$ & $1.07-1.27$ & $1.29-2.37$ & \\
\hline RI NTX mean & $0.69 \pm 0.08$ & $0.67 \pm 0.08$ & $0.69 \pm 0.08$ & \\
\hline $\begin{array}{l}\text { Correlation } \\
\text { coefficient }\end{array}$ & -0.23 & -0.17 & -0.11 & $\mathrm{Chi}^{2}: 1.78$ \\
\hline$p$-Value & 0.19 & 0.37 & 0.55 & $p$-Value: 0.41 \\
\hline Framingham score & $<20$ & $20-30$ & $>30$ & \\
\hline RI NTX mean & $0.68 \pm 0.08$ & $0.74 \pm 0.06$ & $0.68 \pm 0.09$ & \\
\hline $\begin{array}{l}\text { Correlation } \\
\text { coefficient }\end{array}$ & 0.38 & -0.32 & -0.50 & $\mathrm{Chi}^{2}: 5.56$ \\
\hline$p$-Value & $<0.05$ & 0.48 & 0.67 & p-Value: 0.06 \\
\hline Smoking & Non-smoker & & Smoker & \\
\hline RI NTX mean & $0.68 \pm 0.08$ & & $0.67 \pm 0.08$ & \\
\hline $\begin{array}{l}\text { Correlation } \\
\text { coefficient }\end{array}$ & $\mathrm{n} / \mathrm{a}$ & & -0.11 & $\mathrm{Chi}^{2}: 0.63$ \\
\hline$p$-Value & 0.30 & & 0.56 & $p$-Value: 0.43 \\
\hline
\end{tabular}

For indicators marked with $*$, the analyzed categories are based on tertiles. Correlations and their significance were computed using Spearman's rank correlation. RI: Resistance Index, NTX: kidney transplant. GFR: Glomerular Filtration Index, HDL: high density lipoprotein.

prospective cross-sectional cohort received their renal transplant more than 18 months ago. This is important to recognize, as the hemodialysis period and the etiology of the end-stage renal disease as well if the donor was deceased or if it was a living donation and ischemia time have an impact on the transplant-RI. But as discussed above, the RI of the transplant adopts quickly to the recipient and should therefore reflect the recipients RI and not the donors former RI after this period ( $>18$ months) of time. They were consecutively included, regardless of the GFR to give a genuine clinical setting without selection bias.

Heine et al. found that the RI in renal transplants is associated with systemic atherosclerosis as well as subclinical atherosclerotic vessel damage and is, therefore, not only a marker of renal but of vascular damage. They also showed that markers of cardiovascular risk or systemic atherosclerosis are superior outcome predictors for cardiovascular events compared to renal RI $(30,31)$. Heine et al. included 105 renal transplant recipients in their study and used the FRS, the intrarenal RI, the pulsatility index (PI), the IMT, and ABI to assess risk for cardiovascular events and subclinical systemic atherosclerosis in these recipients(13). They concluded that the renal RI rather than a specific marker of renal dysfunction is a complex integration of different factors, including arterial compliance, arterial pulsatility and peripheral resistance. According to Heine et $a l$. , the RI is associated with traditional cardiovascular risk factors and with subclinical atherosclerosis. They also proposed that the RI is not related to the GFR. For this reason, we included patients regardless of renal function as measured by GFR and also found, that the RI seems not to be related to the GFR. However, Heine et. al (or others) did not assess the carotid RI in their work. The carotid RI is technically easier to measure and could also be measured by health care professionals, that are less well trained in more complex renal ultrasound exams. The pathophysiological aspects of the relationship between renal microcirculation and cardiovascular system were further described by di Nicolò and Granata (32). Brennan and Lentine found this result (RI being associated with traditional cardiovascular risk factors and with subclinical atherosclerosis) also in their cohort of patients with kidney transplants. They also used blood samples to measure (amongst others) inflammatory markers. Cardiovascular risk factors and comorbidities were then assessed by a questionnaire. They also studied the risk of coronary heart disease by using the FRS. RI and PI were calculated by CCDS as well as IMT and ABI included in the study data (33). The same parameters were used in our study but also the carotid RI was measured (Heine et al. suggested measurements in native non-renal organs) as well as the AIx. The above shown results are according to the results of Heine et al. and Brennan and Lentine and show that the RI is associated with traditional cardiovascular risk factors. Especially the AIX, that was not measured in the other studies, correlates with subclinical atherosclerosis. AIx is used to measure arterial stiffness as a sign of vascular compliance and was associated with elevated RI. This correlation between RI and changes in vascular compliance/resistance was also shown using an in vitro model (34).

The mechanisms that lead to an increase of the intrarenal RI are still not clarified. While Naesens et al. found, that the transplant kidney is not associated with graft function and graft survival but is associated with recipient survival, Granata et al. proposed, that the transplant kidney RI is increased when tubulointersitial damage is present $(35,36)$. Discrepant findings in the literature and discouraging clinical 
experience led some clinicians to abandon the RI as a reliable parameter. Greater understanding of the theoretical basis of the RI might help the RI to live up to its promise as a parameter for measuring changes in renal status. The RI is sometimes difficult to access, even in transplants. A decreased intrarenal RI can be a sign of a renal stenosis. In patient with orthotope kidneys, the RI can be compared. This is not reasonable if the patient has a transplant kidney. If the observer is in doubt, if a renal graft stenosis is present, the renal-carotid RI may be compared and should be within the same range. In case of the kidney transplant, the RI cannot be compared to an orthotope kidney. The brain is also a parenchymal organ. The RI can be measured in the internal carotid artery. The RI of the internal carotid artery reflects atherosclerotic changes in intracerebral arteries. Chung et al. found that an elevated RI is related to a higher risk of cardiovascular events (37). We could also show that there is a positive association between mean kidney transplant RI and mean internal carotid artery RI, so we propose, that the RI of the internal carotid artery and the kidney transplant are comparable. A next step would be to compare intrarenal RI in patients with renal artery stenosis and the internal carotid RI to harden this suggestion.

We could not show a positive correlation between renal function and RI as described in former studies $(14,38)$. Only patients with a low FRS had a significant correlation with the transplant RI in our cohort, while Heine et al. found that renal transplant recipients with a high cardiovascular risk had increased RIs. There was a significant correlation with CIMT in our study as a sign of elevated cardiovascular risk that was also found in the two above mentioned studies $(13,33)$. As described by Heine et al. we also found no significant correlation between renal function and CIMT.

\section{Conclusion}

Traditional cardiovascular risk factors and markers of subclinical atherosclerosis are related to elevated RIs in renal transplants. As the renal RI is correlated with carotid RI it might be more a general parameter of vascular compliance rather than an exclusive marker of intrarenal resistance. This finding might facilitate the mitigation of the cardiovascular risk in patients with kidney transplants. The measurement of carotid RI is technically easier to perform and could, therefore, be used by a larger number of health associated personnel and as well as used an indirect marker for the suspicion of a renal artery stenosis if there is a gradient in the renal-carotid RI, justifying further imaging with $\mathrm{CT}$ or MRI with potentially graft-harming contrast agent.

\section{Conflicts of Interest}

There are no conflicts of interest.

\section{Authors' Contributions}

P.K. collected data, contributed to the data, wrote the paper and reviewed the paper. S.E. analyzed the data, wrote the paper and reviewed the paper. CT designed the study, collected data, contributed to the data, and reviewed the paper. R.W. took part in the study design, reviewed the results, contributed to the style and reviewed the paper. MLV collected data, contributed to the data, wrote the paper and reviewed the paper. NK reviewed the results, contributed to the style and reviewed the paper. RC designed the study, collected data, contributed to the data, wrote the paper and reviewed the paper.

\section{Acknowledgements}

We thank Elisabeth Beckmann, Ph.D., MsC, MA, BA for the statistical analysis, figures and tables and her support.

\section{References}

1 Axelrod DA, McCullough KP, Brewer ED, Becker BN, Segev DL and Rao PS: Kidney and pancreas transplantation in the United States, 1999-2008: the changing face of living donation. Am J Transplant 10(4 Pt 2): 987-1002, 2010. PMID: 20420648. DOI: $10.1111 / \mathrm{j} .1600-6143.2010 .03022 . \mathrm{x}$

2 Winther S, Svensson M, Jørgensen HS, Rasmussen LD, Holm NR, Gormsen LC, Bouchelouche K, Bøtker HE, Ivarsen P and $\mathrm{B} \emptyset \mathrm{ttcher} \mathrm{M}$ : Prognostic value of risk factors, calcium score, coronary CTA, myocardial perfusion imaging, and invasive coronary angiography in kidney transplantation candidates. JACC Cardiovasc Imaging 11(6): 842-854, 2018. PMID: 28917674. DOI: 10.1016/j.jcmg.2017.07.012

3 Joo KW, Shin SJ, Lee SH, Ha JW, Kim S and Kim YS: Preemptive transplantation and long-term outcome in living donor kidney transplantation, single-center experience. Transplant Proc 39(10): 3061-3064, 2007. PMID: 18089322. DOI: $10.1016 /$ j.transproceed 2007.07 .091

4 Laupacis A, Keown P, Pus N, Krueger H, Ferguson B, Wong C and Muirhead N: A study of the quality of life and cost-utility of renal transplantation. Kidney Int 50(1): 235-242, 1996. PMID: 8807593. DOI: 10.1038/ki.1996.307

5 Li JC, Ji ZG, Cai S, Jiang YX, Dai Q and Zhang JX: Evaluation of severe transplant renal artery stenosis with Doppler sonography. J Clin Ultrasound 33(6): 261-269, 2005. PMID: 16134153. DOI: $10.1002 /$ jcu.20129

6 Thalhammer C, Aschwanden M, Mayr M, Koller M, Steiger J and Jaeger KA: Duplex sonography after living donor kidney transplantation: new insights in the early postoperative phase. Ultraschall Med 27(2): 141-145, 2006. PMID: 16612723. DOI: $10.1055 / \mathrm{s}-2006-926560$

7 Friedewald SM, Molmenti EP, Friedewald JJ, Dejong MR and Hamper UM: Vascular and nonvascular complications of renal transplants: sonographic evaluation and correlation with other imaging modalities, surgery, and pathology. J Clin Ultrasound 33(3): 127-139, 2005. PMID: 15756666. DOI: 10.1002/jcu. 20105

8 Chudek J, Kolonko A, Król R, Ziaja J, Cierpka L and Wiecek A: The intrarenal vascular resistance parameters measured by duplex Doppler ultrasound shortly after kidney transplantation 
in patients with immediate, slow, and delayed graft function Transplant Proc 38(1): 42-45, 2006. PMID: 16504659. DOI: 10.1016/j.transproceed.2005.12.013

9 Aschwanden M, Mayr M, Imfeld S, Steiger J, Jaeger KA and Thalhammer C: Rapid adaptation of the intrarenal resistance index after living donor kidney transplantation. Nephrol Dial Transplant 24(4): 1331-1334, 2009. PMID: 19188340. DOI: $10.1093 /$ ndt/gfp016

10 Radermacher J, Mengel M, Ellis S, Stuht S, Hiss M, Schwarz A, Eisenberger U, Burg M, Luft FC, Gwinner W and Haller H: The renal arterial resistance index and renal allograft survival. $\mathrm{N}$ Engl J Med 349(2): 115-124, 2003. PMID: 12853584. DOI: 10.1056/NEJMoa022602

11 Gupta R, Assiri S and Cooper CJ: Renal artery stenosis: New findings from the CORAL trial. Curr Cardiol Rep 19(9): 75, 2017. PMID: 28752274. DOI: 10.1007/s11886-017-0894-2

12 Gottlieb RH, Snitzer EL, Hartley DF, Fultz PJ and Rubens DJ: Interobserver and intraobserver variation in determining intrarenal parameters by Doppler sonography. AJR Am J Roentgenol 168(3): 627-631, 1997. PMID: 9057503. DOI: 10.2214/ajr.168.3.9057503

13 Heine GH, Gerhart MK, Ulrich C, Köhler H and Girndt M: Renal Doppler resistance indices are associated with systemic atherosclerosis in kidney transplant recipients. Kidney Int $68(2)$ : 878-885, 2005. PMID: 16014069. DOI: 10.1111/j.1523$1755.2005 .00470 . \mathrm{x}$

14 Krumme B, Grotz W, Kirste G, Schollmeyer P and Rump LC: Determinants of intrarenal Doppler indices in stable renal allografts. J Am Soc Nephrol 8(5): 813-816, 1997. PMID: 9176852. DOI: 10.1681/ASN.V85813

15 Frauchiger B, Schmid HP, Roedel C, Moosmann P and Staub D: Comparison of carotid arterial resistive indices with intimamedia thickness as sonographic markers of atherosclerosis. Stroke 32(4): 836-841, 2001. PMID: 11283379. DOI: 10.1161/ 01.str.32.4.836

16 Gerhart MK, Seiler S, Grün OS, Rogacev KS, Fliser D and Heine GH: Indices of systemic atherosclerosis are superior to ultrasound resistance indices for prediction of allograft survival. Nephrol Dial Transplant 25(4): 1294-1300, 2010. PMID: 19945953. DOI: 10.1093/ndt/gfp631

17 Seibert FS, Behrendt C, Pagonas N, Bauer F, Kiziler F, Zidek W and Westhoff TH: Prediction of cardiovascular events after renal transplantation. Transplant Proc 47(2): 388-393, 2015. PMID: 25769579. DOI: 10.1016/j.transproceed.2014.12.014

18 Levey AS, Stevens LA, Schmid CH, Zhang YL, Castro AF 3rd, Feldman HI, Kusek JW, Eggers P, Van Lente F, Greene T, Coresh J and CKD-EPI (Chronic Kidney Disease Epidemiology Collaboration): A new equation to estimate glomerular filtration rate. Ann Intern Med 150(9): 604-612, 2009. PMID: 19414839. DOI: 10.7326/0003-4819-150-9-200905050-00006

19 Girometti R, Stocca T, Serena E, Granata A and Bertolotto M: Impact of contrast-enhanced ultrasound in patients with renal function impairment. World J Radiol 9(1): 10-16, 2017. PMID: 28144402. DOI: $10.4329 /$ wjr.v9.i1.10

20 Mueller-Peltzer K, Negrão de Figueiredo G, Fischereder M, Habicht A, Rübenthaler J and Clevert DA: Vascular rejection in renal transplant: Diagnostic value of contrast-enhanced ultrasound (CEUS) compared to biopsy. Clin Hemorheol Microcirc 69(1-2): 77-82, 2018. PMID: 29630540. DOI: $10.3233 / \mathrm{CH}-189115$
21 Lam NN, Klarenbach S, Quinn RR, Hemmelgarn B, Tonelli M, Ye F, Ravani P, Bello AK, Brennan DC and Lentine KL: Renal function, albuminuria, and the risk of cardiovascular events after kidney transplantation. Transplant Direct 4(10): e389, 2018. PMID: 30498766. DOI: 10.1097/TXD.0000000000000828

22 Tublin ME, Bude RO and Platt JF: Review. The resistive index in renal Doppler sonography: where do we stand? AJR Am J Roentgenol 180(4): 885-892, 2003. PMID: 12646425. DOI: 10.2214/ajr.180.4.1800885

23 Rifkin MD, Needleman L, Pasto ME, Kurtz AB, Foy PM, McGlynn E, Canino C, Baltarowich OH, Pennell RG and Goldberg BB: Evaluation of renal transplant rejection by duplex Doppler examination: value of the resistive index. AJR Am J Roentgenol 148(4): 759-762, 1987. PMID: 3548286. DOI: 10.2214/ajr.148.4.759

24 Rigsby CM, Burns PN, Weltin GG, Chen B, Bia M and Taylor KJ: Doppler signal quantitation in renal allografts: comparison in normal and rejecting transplants, with pathologic correlation. Radiology 162(1 Pt 1): 39-42, 1987. PMID: 3538151. DOI: 10.1148/radiology.162.1.3538151

25 London NJ, Aldoori MI, Lodge VG, Bates JA, Irving HC and Giles GR: Reproducibility of Doppler ultrasound measurement of resistance index in renal allografts. Br J Radiol 66(786): 510513, 1993. PMID: 8330135. DOI: 10.1259/0007-1285-66-786510

26 Päivärinta J, Oikonen V, Räisänen-Sokolowski A, Tolvanen T, Löyttyniemi E, Iida H, Nuutila P, Metsärinne K and Koivuviita $\mathrm{N}$ : Renal vascular resistance is increased in patients with kidney transplant. BMC Nephrol 20(1): 437, 2019. PMID: 31775670. DOI: $10.1186 / \mathrm{s} 12882-019-1617-2$

27 Boran M, Boran E, Boran M and Tola M: Renal Doppler resistance indices in kidney transplant recipients with proteinuria. Transplant Proc 50(5): 1355-1359, 2018. PMID: 29880357. DOI: 10.1016/j.transproceed.2018.02.064

28 Dupont PJ, Dooldeniya M, Cook T and Warrens AN: Role of duplex Doppler sonography in diagnosis of acute allograft dysfunction-time to stop measuring the resistive index? Transpl Int 16(9): 648-652, 2003. PMID: 12768233. DOI: 10.1007/ s00147-003-0601-7

29 Kramann R, Frank D, Brandenburg VM, Heussen N, Takahama J, Krüger T, Riehl J and Floege J: Prognostic impact of renal arterial resistance index upon renal allograft survival: the time point matters. Nephrol Dial Transplant 27(10): 3958-3963, 2012. PMID: 22247231. DOI: $10.1093 /$ ndt/gfr772

30 Thalhammer C, Aschwanden M, Mayr M, Staub D and Jaeger KA: Colour-coded duplex sonography after renal transplantation. Ultraschall Med 28(1): 6-21; quiz 25, 2007. PMID: 17304409. DOI: $10.1055 / \mathrm{s}-2007-962859$

31 Gerhart MK, Seiler S, Grün OS, Rogacev KS, Fliser D and Heine GH: Indices of systemic atherosclerosis are superior to ultrasound resistance indices for prediction of allograft survival. Nephrol Dial Transplant 25(4): 1294-1300, 2010. PMID: 19945953. DOI: $10.1093 /$ ndt/gfp631

32 Di Nicolò P and Granata A: Renal Resistive Index: not only kidney. Clin Exp Nephrol 21(3): 359-366, 2017. PMID: 27530995. DOI: $10.1007 / \mathrm{s} 10157-016-1323-3$

33 Brennan DC and Lentine KL: Is there a correlation between atherosclerosis and renal resistive indices in kidney transplant recipients? Nat Clin Pract Nephrol 2(2): 64-65, 2006. PMID: 16932391. DOI: 10.1038/ncpneph0090 
34 Bude RO and Rubin JM: Relationship between the resistive index and vascular compliance and resistance. Radiology 211(2): 411-417, 1999. PMID: 10228522. DOI: 10.1148/radiology.211.2. r99ma48411

35 Granata A, Zanoli L, Clementi S, Fatuzzo P, Di Nicolò P and Fiorini F: Resistive intrarenal index: myth or reality? Br J Radiol 87(1038): 20140004, 2014. PMID: 24734937. DOI: $10.1259 /$ bjr.20140004

36 Naesens M, Heylen L, Lerut E, Claes K, De Wever L, Claus F, Oyen R, Kuypers D, Evenepoel P, Bammens B, Sprangers B, Meijers B, Pirenne J, Monbaliu D, de Jonge H, Metalidis C, De Vusser $\mathrm{K}$ and Vanrenterghem Y: Intrarenal resistive index after renal transplantation. N Engl J Med 369(19): 1797-1806, 2013. PMID: 24195547. DOI: 10.1056/NEJMoa1301064
37 Chung H, Jung YH, Kim KH, Kim JY, Min PK, Yoon YW, Lee BK, Hong BK, Rim SJ, Kwon HM and Choi EY: Carotid artery end-diastolic velocity and future cerebro-cardiovascular events in asymptomatic high risk patients. Korean Circ J 46(1): 72-78, 2016. PMID: 26798388. DOI: 10.4070/kcj.2016.46.1.72

38 Restrepo-Schäfer IK, Schwerk WB, Müller TF, Prinz H, Görg C and Arnold R: [Intrarenal doppler flow analysis in patients with kidney transplantation and stable transplant function]. Ultraschall Med 20(3): 87-92, 1999. PMID: 10444777. DOI: $10.1055 / \mathrm{s}-1999-14242$

Received July 4, 2021

Revised August 23, 2021

Accepted August 31, 2021 